\title{
SCHEDULING WORK UNDER INTEGRATED URBAN DEVELOPMENT USING THE METHOD OF UNCERTAIN RESOURCE COEFFICIENTS
}

\author{
Sergey Bolotin ${ }^{1 *}$, Haitham Bohan¹, Aldyn-kys Dadar², Khenzig Biche-ool \\ ${ }^{1}$ Saint Petersburg State University of Architecture and Civil Engineering \\ Vtoraja Krasnoarmeyskaya st., 4, Saint Petersburg, Russia \\ ${ }^{2}$ Tuvan State University \\ Lenin st., 36, Kyzyl city, Republic of Tuva, Russia
}

*Corresponding author: sbolotin@mail.ru

\begin{abstract}
Introduction: Planning integrated development of a residential area involves determining the composition of the objects to be built and creating an appropriate integration mechanism, backed up by a generalized work schedule. The existing methods of forming integrated work schedules do not use a systemic approach, based on a universal mathematical model, to describe the organizational and technological aspects of construction. Methods: The present study uses the method of uncertain resource coefficients to demonstrate a mechanism for systemically describing organizational and technological construction processes. We present a way of adapting this method to forming a generalized construction schedule during integrated development. The proposed adaptation mechanism is based on managing schedule calculations by rationally influencing the elements of the linear equation system that describes the organizational and technological processes. Results and Discussion: The solutions presented in the paper are fully consistent with the calculations obtained by different flow methods of organizing construction, as well as with the critical path method used in project management programs. The method described in the paper has been implemented in well-known project management software, Microsoft Project, as a macro program in the Visual Basic for Applications programming language, making it possible to form, calculate, and optimize a schedule for integrated territory development using the unified software toolkit.
\end{abstract}

\section{Keywords}

Calendar construction scheduling, organizational and technological construction plan, temporal collisions of calendar schedules, admissible work scheduling, project management software.

\section{Introduction}

The fundamentals and main principles underpinning the integrated development of residential areas are reflected in the Urban Planning Code of the Russian Federation (Garant, 2021) and can be listed as follows:

- The aim of developing urban areas is to ensure favorable and comfortable living and use.

- Urban planning activities must consider all factors: economic, environmental, manmade, and social.

- $\quad$ The government is responsible for providing the population with favorable living conditions.

Article 65 of the Urban Planning Code, "Types of Integrated Urban Development", can serve as the framework for implementing the principles presented.

A large number of scientific works have been published on the topic of integrated urban development. We shall not aspire to comprehensively cover the entirety of integrated development research, presenting instead a brief overview. Babenko (2013) studied general issues and prospects of implementing the concept of integrated urban development in large Russian cities. In turn, Lychkovsky and Sayenko (2017) provided specific data on the ratio of residential spaces to the total size of infrastructure and amenities required for creating essential comfortable living conditions. In this regard, it should be noted that the make-up of construction projects is defined as early as during initial planning, which points to the need for considering the future building contractors' specialization and requires their hierarchical integration. Public-private partnerships would be the most rational framework for such integration (Voronina and Fentisova, 2016).

A rational consequence of using any integration mechanism is the development of a generalized work schedule that helps synchronize the construction of various facilities as part of integrated urban development. This kind of consolidated work scheduling has been referred to with various terms at different times and for different reasons: integrated consolidated construction schedules, generalized network models, multi-projects, etc. The name change has its own background, but that subject is more relevant to historiographic studies. In this paper, it would be more appropriate to consider how to make 
generalized (integrated) work scheduling calculations.

The formation of work schedules can be based on different aspects of construction organization. For instance, it can focus on lean construction (Petrochenko, 2018) or on accelerated construction (Leach, 2010). We focus on obtaining such an integrated development schedule that would ensure the synchronization of construction tasks, subject to a systemic description of the organizational and technological plan under various time constraints.

The calculation of integrated work scheduling is a consistent attribute of project management software. As an example, we can cite such wellknown software products as Primavera (Bovteyev and Tsvetkov, 2008) and Microsoft Project (Kupershtein, 2010). Further in the study, we will use the capabilities of Microsoft Project, since it allows for addressing special tasks relevant to work scheduling in the Visual Basic for Applications programming language. The calculation of work scheduling in this software and its counterparts is based on the critical path method. The result of calculating the overall schedule is obtained through step-by-step sorting of all preceding tasks and events affecting the time characteristics of subsequent tasks.

Here it should be noted that such step-by-step calculation can be significantly complicated by the fairly high likelihood of various time conflicts or collisions. This can be explained by the fact that planning the development of a given site cluster may be accompanied by multiple resource and time constraints. However, because sequential calculation is embedded in project management software, each iteration performed at each step is accompanied by a message that it will be impossible to complete the given task at the given time due to scheduling conflicts. Next, Microsoft Project and similar software offer the following recommendations:

- to change the type of constraints;

- $\quad$ to remove the ties between conflicting tasks;

- to make the tasks shorter;

- to change the dates related to work scheduling.

If the task is complex, then all of the recommendations above apply to the simple subtasks therein. In other words, unpredictable time conflicts arise during the calculation of an integrated schedule, and the step-by-step elimination of time conflicts makes the calculation much more laborintensive and creates various hidden errors.

Network planning methods are not the only basis for designing calendar schedules in construction. Flow methods of construction organization are also used in global construction practice. They can have different names in different studies (El-Rayes and Moselhi, 1998; Selinger, 1980). Flow-type organization of integrated urban development, geared for application in the Russian Federation, was described by Chelnokova (2016).
She also emphasized the need to determine a rational sequence of projects in integrated urban development (Chelnokova, 2015). To implement the process of finding an optimal sequence, various algorithms are used, mainly based on the principle of targeted option sorting (Hejducki and Rogalska, 2011; Rogalska et al., 2008).

Yet if an optimal solution is being searched through targeted sorting (Chelnokova, 2015; Hejducki and Rogalska, 2011; Rogalska et al., 2008), a situation may occur where it will become impossible to actually complete development under the criterion selected. This happens because the purely mathematical search for an optimal construction sequence overlooks the possible spatial constraints affecting facility commissioning. For example, a facility may be fully built, but its commissioning may be hindered by the construction of other facilities. This collision is quite predictable when BIM modeling is used to visualize the cluster development process (Bolotin and Dadar, 2020; Bolotin et al., 2019). However, in this case, construction sequence optimization is needed, based not on the targeted sorting principle as outlined in (Chelnokova, 2015; Hejducki and Rogalska, 2011; Rogalska et al., 2008), but on the principle of exhaustive sorting of all options, in the form of macro software (Bolotin et al., 2011). This can be explained as follows: if previously obtained optimal options need to be scrapped, the exhaustive sorting principle will always offer some other backup options.

Our analysis exposes the causes of ineffective planning under integrated urban development, which directly depend on the non-systemic approach to calculating the overall construction scheduling. Thus, there is a need to develop a new approach to eliminating time conflicts, based on replacing step-by-step iterations with a systemic definition and analysis of calculation procedures.

\section{Methods}

The approach that we propose is related to using the method of uncertain resource coefficients, which was described in a number of works, e.g. by Bolotin et al. (2005). Let us consider its essence. During the initial stage of calculating the total duration of construction, the assumption is that each of the work tasks is performed within the minimum possible time $t_{\min }$, and thus that the labor resources are at their maximum, $R_{\max }$

$$
t=t_{\text {min }}+a \cdot t_{\text {min }}
$$

where $a$ is the unknown resource coefficient; its introduction allows for determining the addition to minimum duration, defined as a linear dependence.

The functional relationship between the resource coefficient and the value of unknown resources $R$ is defined by the following equation: 


$$
a=\left(R_{\max } / R\right)-1
$$

If we assume for the duration of individual work tasks to be minimal, the total estimated construction duration will also equal the minimum value, $T_{\min }$. This gives us a reference point for assigning the corresponding directive duration of construction $T_{d}$, which should have a larger value. As a result, the $T_{d}-T_{\min }$ difference will have a positive value. This difference represents the time reserve that can be used to increase the duration of individual tasks or to minimize the initially assigned resources. According to Bolotin et al. (2005), if the duration of all types of work is represented in accordance with Eqs. (1) and (2), minimizing the labor resources will be equivalent to maximizing the sum total of work duration.

In order to explain how to adapt the uncertain resource coefficient method to the task at hand, let us consider one case study of integrated urban development. Figure 1 shows the corresponding organizational and technological plan.

The integrated urban development comprises 9 buildings. They include: 4 panel buildings designed as permanent residences, 2 brick buildings (hostels) designed as temporary residences, and 3 buildings with educational functions, including a school, a kindergarten (day care), and a youth art center. For facilities of this kind, it is not too difficult to determine the minimum work duration because there are corresponding recommended values defined by the construction duration norms (Repository for legal documents, standards, regulations, and specifications, 2021).

In Figure 1, each rectangle is labeled with the individual task's name, as well as task duration in weeks. The durations of all the work tasks (in weeks), calculated using the critical path method, are shown under respective rectangles. All panel buildings are integrated into a single construction flow, with a specified order of construction for each building. The calculations show that the last building of the given flow can be commissioned into operation 177 weeks after the start of construction. The brick hostel buildings form a separate construction flow; these are to be completed within 99 weeks. The third construction flow includes the educational buildings, all of which will be completed by the $135^{\text {th }}$ week. That said, there are two types of time constraints imposed on this flow: work must start not earlier than within 1 year (52 weeks) and end not later than in 3 years (156 weeks). As a result, the estimated final construction deadline for the above urban cluster



Figure 1. Case study for an organizational and technological plan of integrated urban development 
is 177 weeks. However, the official schedule set by the administrative authorities is limited to 4 years, or 208 weeks.

As per the method of uncertain resource coefficients, any organizational and technological plan can be described with a system of linear equations. The composition of variables included in the system of equations is illustrated in Figure 1. Related tasks of the same type have resource connections denoted as $r c_{k}$. The total number of such connections for the organizational and technological plan in question is 20 . The related tasks determining the technological sequence for the execution of different work task types are linked with frontal connections denoted as $f_{i}$. Their total number in this particular case is 21 . The variables determining task duration from the overall project beginning to the completion of initial tasks of each type are defined as beginning connections: $b c_{i}$. The variables determining task duration from the completion of the final tasks of each type to the overall project end are defined as end connection: $e_{i \text {. }}$. The total number of both types of connections is equal to the total number of work types, i.e. 10. The same number of variables defines the unknown resource coefficients found via Eq. (2).

The timing for each of the tasks included in the total work schedule can be limited. The "starting not earlier than" restriction type is defined by the relevant date, whereas the difference between this date and the unknown beginning of work execution is defined by a variable designated as $n b_{l}$. The "finishing not earlier than" restriction type is also defined by the relevant date, whereas the difference between this date and the unknown end of work execution is defined by a variable designated as $n e$. The plan shown in Figure 1 includes one example of each such restriction type. This brings the total number of variables shown in Figure 1 to 73 .

The equations describing the organizational and technological plan are classified into three groups. The first group of equations includes resource equations, comprising tasks of one type. Let us present two examples of resource equations.

$$
\begin{aligned}
& b c_{1}+20 a_{1}+r c_{1}+r c_{2}+r c_{3}+e c_{1}=188 . \\
& b c_{2}+48 a_{2}+r c_{4}+r c_{5}+r c_{6}+e c_{2}=160 .
\end{aligned}
$$

The plan presented in Figure 1 is ultimately described by 10 resource equations.

As noted above, the technological sequence determining the order of the first and second work types at each of the sites is defined by a respective frontal connection. Therefore, a frontal equation is composed for each such connection. Two equation examples are shown below.

$$
b c_{1}+5 a_{1}+f c_{1}+48 a_{2}+r c_{4}+r c_{5}+r c_{6}+e c_{2}=157 .(5)
$$

$$
b c_{1}+9 a_{1}+r c_{1}+f c_{2}+35 a_{2}+r c_{5}+r c_{6}+e c_{2}=164 .
$$

The plan shown in Figure 1 is described by 12 frontal equations for the group of residential buildings, 6 equations for the group of hostels, and 3 equations for the group of educational institutions. Overall, we have 21 frontal equations.

The third group limits the time for the execution of individual tasks and is therefore defined as a group of restricted equations. This group is represented by two equations.

$$
\begin{aligned}
& n b_{1}+12 a_{9}+r c_{17}+r c_{18}+e c_{9}=144 . \\
& b c_{10}+77 a_{10}+r c_{19}+r c_{20}+n e_{2}=79
\end{aligned}
$$

As a result, the organizational and technological plan shown in Figure 1 is described by 33 equations that include 73 variables. The ultimate system of equations, formed as described above, perfectly identifies the organizational and technological plan of integrated urban development.

In linear programming, a system of equations of this kind is called a simplex (Bunday, 1989), and its optimized solution has two stages. The first stage involves searching for a feasible basic solution via forming an artificial target function. As noted in (Bunday, 1989), the assumption is that the order of introducing variables into the feasible basic solution does not matter for most problems solved using the linear programming method. However, it is possible to demonstrate that for the problem we have set, the order of variable input defines the flow organization method for construction works (Afanasyev, 1990).

The second stage involves forming an optimization solution for the system of linear equations, which can be focused on minimizing labor resources. This is achieved with the following target function:

$$
\begin{aligned}
& Z=20 a_{1}+48 a_{2}+146 a_{3}+54 a_{4}+9 a_{5}+27 a_{6} \\
& +70 a_{7}+17 a_{8}+12 a_{9}+77 a_{10} \rightarrow \max .
\end{aligned}
$$

This target function defines the maximization of the total duration for all work tasks included in integrated urban development. In the case study presented, the estimated duration is 177 weeks, whereas the corresponding directive duration is 208 weeks. This determines the time reserve necessary to minimize 10 types of resources.

Let us presents calculations for the maximum number of options using the principle of exhaustive sorting of all construction sequence options. It can be determined by multiplying the number of options for each of the distinguished flows. The first flow includes 4 facilities, which gives 4 ! $=24$ rearrangement options, while the second flow has 2 rearrangement options, and the third flow has 6 rearrangement options. Thus, we obtain 288 development options, and 
this number determines the limit of computational complexity regarding this problem.

\section{Results and Discussion}

If all resource connections in the initial simplex matrix are moved to the end, then it becomes possible to obtain the solution for the system of equations with zero values of resource connections, by searching for the next basic variable with a forced return to the beginning. This solution is shown in Figure 2.

Figure 2 shows the values of basic variables that determine the duration of corresponding connections. The number of basic variables is equal to the number of equations. If (Figure 2) a corresponding variable is missing after the equation sign, it means that the given variable is free, and its value is, by definition, zero. This option of solving the problem shows that all resource connections have turned out to be free variables. This means that the feasible basic solution is equivalent to the method of calculating construction flow organization during continuous resource usage. The calculation also shows that, in order to fully complete building the given cluster, construction activities can be launched at later dates of event occurrence. This occurs because the beginning connections are entered into the basis first, followed by the end connections. If you change the order of input, you can get the solution for earlier dates of event occurrence.

After assessing the obtained work schedule, we can conclude that it is inexpedient to form generalized scheduling in accordance with the principle of continuous resource usage. In fact, large breaks between adjacent tasks in the technological work sequence are quite typical of this type of scheduling. For example, the completion of preparatory works for the fourth building should be followed by a 21-week break, which is found unacceptable in real-life construction.

In the proposed method, eliminating such shortcomings takes just a change in the order of introducing variables into the basis. If the variables modeling the frontal connections are placed at the end of the simplex matrix, this will yield a solution with zero values of frontal connections (Figure 3 ). In addition, the end connections could be moved to the top position in the simplex, bringing the problem solution closer

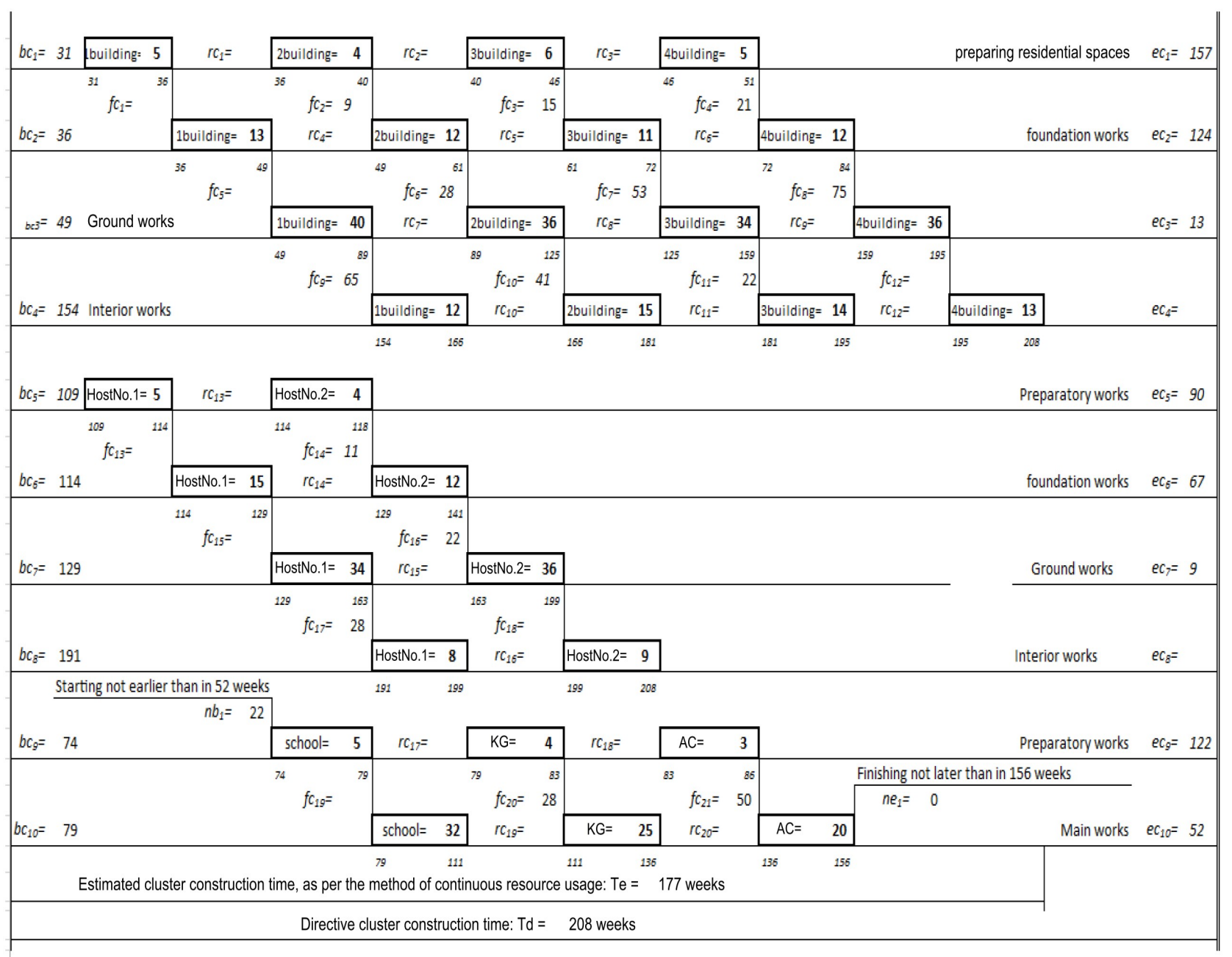

Figure 2. Calculating the schedule of integrated urban development when resource usage is continuous 


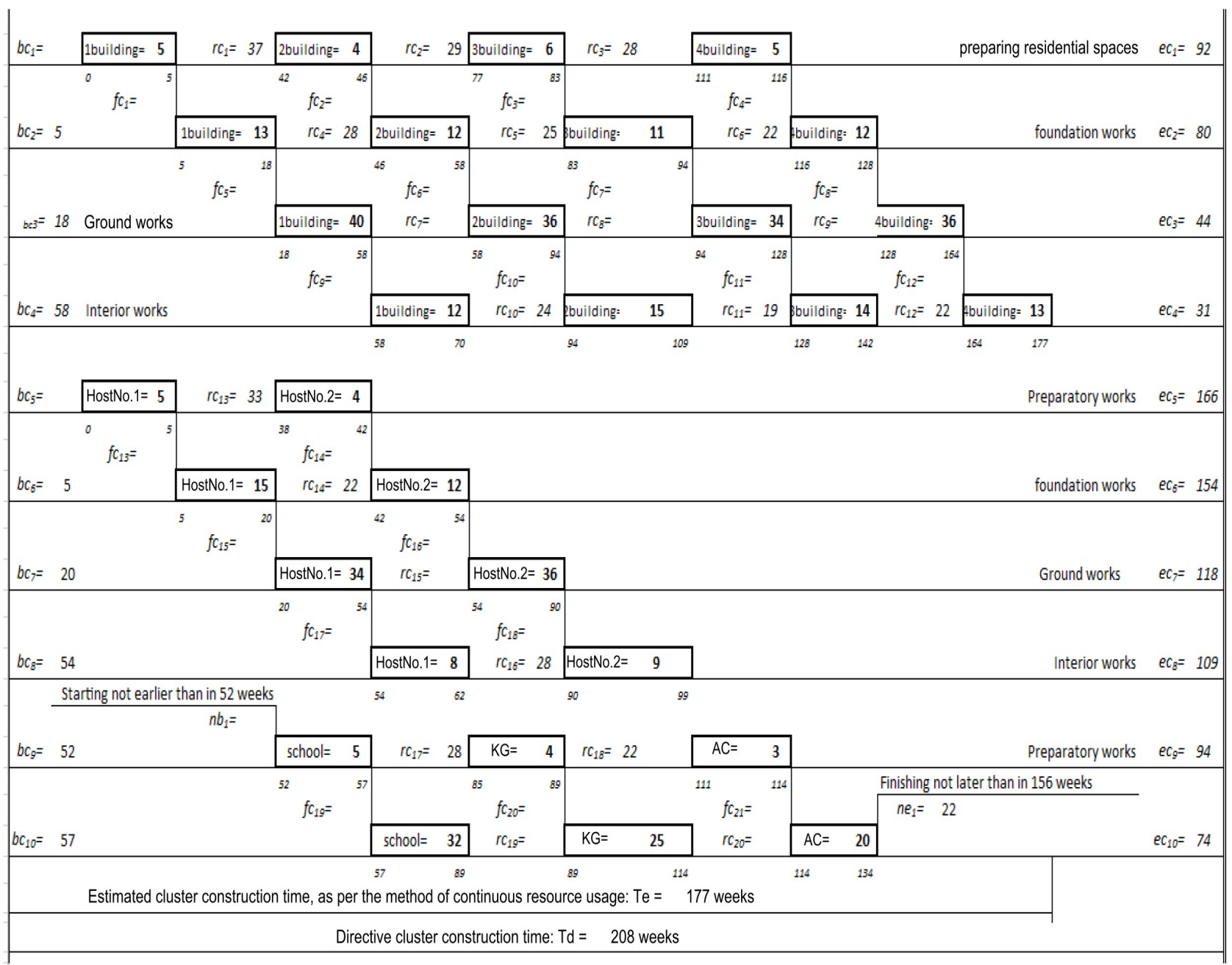

Figure 3. Calculating the schedule of integrated urban development for the case study territory with the use of the method of uncertain resource coefficients, provided that the work scope is continuously expanding

to calculating earlier dates of event occurrence.

As can be seen from Figure 3 , the solution obtained fully corresponds to the calculation of construction flow organization, using the method with a continuous expansion of work scope, as described in a number of monographs (Afanasyev, 1990; Hejducki and Rogalska, 2011). In addition to the solution options reviewed, it is possible to obtain an alternative solution, which corresponds to the traditional use of the critical path method.

Moreover, it is possible to obtain an admissible solution in cases when the number of basic variables is lower than the number of equations. This situation reflects the inconsistency of the resulting equation system, due to the aforementioned time collision. The following procedure has been developed and implemented in order to address this collision. In the equation that lacks the basic variable, it is necessary to change all signs to the opposite. Then the standard algorithm for finding the basic solution needs to be re-applied to the new system of equations. The resulting solution will be a basic solution, albeit not admissible because the basic variables will have negative values. Negative values can be included in time lags when connections are formed between those work tasks that can partially be completed simultaneously. If the work conditions allow, it is also possible to increase the maximum amount of labor resources so that the negative time reserve reaches zero. Other options, found through transforming the system of equations describing integrated urban development scheduling, are also viable.

\section{Conclusion}

This study is aimed at adapting the method of uncertain resource coefficients to form generalized construction schedules for integrated urban development. The proposed adaptation mechanism is based on managing work scheduling calculations through a rational impact on the elements of the linear equation system describing the organizational and technological plan of construction activities. 


\section{References}

Afanasyev, V. A. (1990). Construction workflow. Moscow: Stroyizdat, 302 p.

Babenko, S. V. (2013). Problems and prospects of implementing complex development concept in capital cities of Russia. Journal of Legal and Economic Studies, No. 2, pp. 137-140.

Bolotin, S. A., Biche-ool, Kh. V. and Dadar, A.-K. Kh. (2019). Scheduling visualization methodology in Autodesk Revit 2018. Bulletin of Civil Engineers, No. 6 (77), pp. 179-185. DOI: 10.23968/1999-5571-2019-16-6-179-185.

Bolotin S. A. and Dadar, A. H. (2020). Methodology of setting priorities in integrated development of territories using BIM software and project management. Real Estate: Economics, Management, No. 1, pp. 57-62.

Bolotin, S. A., Dadar, A. Kh., Meshchaninov, I. Yu. and Oolakaj, Z. Kh. (2011). Energy and resource saving objects' reconstruction sequence elimination with the regard for heterogenous limitations for the search for optimum. Bulletin of Civil Engineers, No. 3(28), pp. 60-65.

Bolotin, S. A., Klimov, S. E. and Simankina, T. L. (2005). Optimization of resource distribution under calendar scheduling using the method of uncertain resource coefficients. Scientific Herald of the Voronezh State University of Architecture and Civil Engineering. Construction and Architecture, No. 1, p. 101.

Bovteyev, S. V. and Tsvetkov, A. V. (eds.) (2008). Managing investment construction projects on the basis of Primavera. Moscow, Saint Petersburg: PMSOFT, Saint Petersburg State University of Architecture and Civil Engineering, 455 p.

Bunday, B. (1989). Basic linear programming. Moscow: Radio i Svyaz, 176 p.

Chelnokova, V. M. (2015). Determination of rational priority of project construction in calendar planning of complex development of the territory. Bulletin of Civil Engineers, No. 2 (49), pp. 102-106.

Chelnokova, V. M. (2016). Features of calendar scheduling of complex development of the territory by the development organization. Bulletin of Civil Engineers, No. 3 (56), pp. 136-142.

El-Rayes, K. and Moselhi, O. (1998). Resource-driven scheduling of repetitive activities. Construction Management and Economics, Vol. 16, Issue 4, pp. 433-446. DOI: 10.1080/014461998372213.

Hejducki, Z. and Rogalska, M. (2011). Time coupling methods construction scheduling and time/cost optimization. Wroclav: Oficyna Wydawnicza Politechniki Wroclawskiej, 91 p.

Kupershtein, V. I. (2010). Microsoft Project 2010 in project management. Saint Petersburg: BKhV-Peterburg, 416 p.

Leach, L. (2010). On time and on budget. Critical chain project management. Moscow: Alpina Publisher, 354 p.

Lychkovsky, D. A. and Sayenko, I. A. (2017). Integrated development as a priority for the development of urban areas. Economic Development Research Journal, No. 6, pp. 128-134.

Petrochenko, M. V. (2018). Organization and planning in construction. Fundamentals of lean construction. Part 1. Study guide. Saint Petersburg: Publishing House of Polytechnic University, 208 p.

Repository for legal documents, standards, regulations, and specifications (2021). Construction Rules and Regulations SNiP 1.04.03-85. Norms of construction duration and backlog in the construction of enterprises, buildings, and structures. [online]. Available at: http://docs.cntd.ru/document/1200000622 [Date accessed November 21, 2021].

Rogalska, M., Bożejko, W. and Hejducki, Z. (2008). Time/cost optimization using hybrid evolutionary algorithm in construction project scheduling. Automation in Construction, Vol. 18, pp. 24-31.

Selinger, S. (1980). Construction planning for linear projects. Journal of the Construction Division, Vol. 106, Issue 2, pp. 195-205.

Garant (2021). Urban Planning Code of the Russian Federation No. 190-FZ dated December 29, 2004. [online]. Available at: https://base.garant.ru/12138258/ [Date accessed November 21, 2021].

Voronina, N. V. and Fentisova, I. V. (2016). Development of public-private parthership in the complex housing development of territories. In: Kourov, V. F. (ed.) Current Issues in the Economic Development of Enterprises, Industries, Sectors, and Territories. Proceedings of the International Research and Practice Conference. In 2 volumes. Vol. 2. Khabarovsk: Pacific National University, pp. 33-36. 


\title{
ФОРМИРОВАНИЕ РАСПИСАНИЯ РАБОТ ПРИ КОМПЛЕКСНОМ ОСВОЕНИИ ТЕРРИТОРИИ МЕТОДОМ НЕОПРЕДЕЛЕННЫХ РЕСУРСНЫХ КОЭФФИЦИЕНТОВ
}

\author{
Сергей Алексеевич Болотин ${ }^{1 *}$, Хайтам Абдулраззак Бохан ${ }^{1}$, Алдын-кыс Хунаевна Дадар ${ }^{2}$, Хензиг \\ Владиславовна Биче-оол ${ }^{1}$
}

${ }^{1}$ Санкт-Петербургский государственный архитектурно-строительный университет 2-ая Красноармейская ул., 4, Санкт-Петербург, Россия

${ }^{2}$ Тувинский государственный университет

Ленина ул., 36, Кызыл, Республика Тыва, Россия

*E-mail: sbolotin@mail.ru

\begin{abstract}
Аннотация
При планировании комплексного освоения селитебной территории определяется состав строящихся объектов, под который создается соответствующий интеграционный механизм, функционирующий на основе формирования обобщенного расписания работ. Существующие методы формирования комплексных расписаний работ не используют системный поход при описании организационно-технологической схемы строительства, базирующийся на универсальной математической модели. Методы: В настоящем исследовании, использующем метод неопределенных ресурсных коэффициентов, показан механизм системного описания организационнотехнологической схемы строительства. Представлена адаптация этого метода к решению задачи по формированию обобщенного расписания строительства при комплексном освоении территории. Предлагаемый механизм адаптации основан на управлении расчетом расписания работ посредством рационального воздействия на элементы системы линейных уравнений, описывающих организационно-технологическую схему. Результаты и обсуждение: Представленные в статье решения полностью соответствует расчетам, полученным с помощью разных поточных методов организации строительства, а также используемому в программах управления проектами методу критического пути. Описанная в статье методика реализована в широко известной программе управления проектами типа Microsoft Project в форме программы-макроса на языке программирования Visual Basic for Applications, что позволяет фрормировать, рассчитывать и оптимизировать расписание по комплексному освоению территории с помощью единого программного инструментария.
\end{abstract}

Ключевые слова

Календарное планирование строительством, организационно-технологическая схема строительства, временные коллизии календарных графиков, допустимое расписание работ, программы управления проектами. 